\title{
A interlocução teórica entre Francisco de Oliveira e Celso Furtado: pensamento crítico e ação reformadora
}

\author{
Alex Hotz Moret \\ Pontifícia Universidade Católica de São Paulo, Brasil \\ (iD) https://orcid.org/0000-0002-6194-2320 \\ alexhmoret@gmail.com
}

\section{Introdução}

Neste trabalho pretendemos analisar a interlocução crítica feita por Francisco de Oliveira ao pensamento dualista cepalino, que teve Celso Furtado como o maior expoente. Essa crítica formulada por Oliveira marca sua produção teórica e foi responsável por lançar o autor na discussão da realidade econômica nacional, tornando-se bibliografia obrigatória no estudo do desenvolvimento capitalista brasileiro.

Mostraremos que o debate teórico feito por Francisco de Oliveira ao pensamento furtadiano não está somente no ensaio de 1972, $A$ Economia Brasileira: Crítica à Razão Dualista, futuramente transformado no livro Crítica à razão dualista (2003) como também na obra Elegia para uma Re(li)gião: SUDENE, Nordeste, Planejamento e conflitos de classes (1977). Neste último trabalho, Francisco de Oliveira 
fez uma discussão diretamente relacionada às propostas de reforma do Nordeste brasileiro apresentadas por Celso Furtado e dialogou com a produção furtadiana para o Nordeste, que tinha em sua essência a regionalização e aplicação das teses cepalinas para o contexto da economia brasileira.

Será demonstrado que Francisco de Oliveira, ao elaborar sua crítica ao pensamento cepalino furtadiano, apresentou nova forma de compreensão do processo de expansão capitalista nacional, principalmente por produzir uma análise que inseriu elementos relacionados a fatores sociais, políticos e econômicos internos.

Por fim, pretendemos relatar que a interlocução teórica elaborada por Oliveira não nega completamente os argumentos apresentados na obra furtadiana. De fato, trata-se de uma tentativa de inserir novos elementos para a compreensão da realidade nacional. Vale dizer que a análise de Oliveira complementava lacunas teóricas que se apresentavam nas formulações furtadiana. Além disso, é importante enfatizar que Francisco de Oliveira sempre considerou o professor Celso Furtado com um dos mais importantes intelectuais brasileiros - cuja obra é bibliografia obrigatória para a compreensão da realidade nacional - e justamente por isso, será constantemente merecedora de análises criteriosas. O debate teórico que será apresentado neste trabalho é, na realidade, um encontro entre dois importantes pensadores brasileiros que deve ser memorado, compreendido e servir como ferramenta capaz de contribuir para a formação dos cientistas sociais brasileiros.

Antes de apresentarmos a interlocução crítica produzida por Francisco de Oliveira, iremos expor as principais ideias do pensamento cepalino furtadiano, que serão discutidas por Oliveira na primeira fase de sua produção teórica, assim como contextualizar o momento histórico no qual o debate teórico foi construído. 
É importante ressaltar que a partir da década de 1950, o pensamento econômico brasileiro passa a ser elaborado no bojo de tendências e ideologias distintas que disputam espaço no cenário teórico intelectual brasileiro. Essa discussão desenvolve-se concomitantemente com a fase de consolidação do Brasil como um país urbano-industrial e traz um debate que reflete os interesses das classes dominantes e projetos distintos de transformação nacional.

Nesse contexto, surgem no Brasil pensadores econômicos de diversas correntes que passam a contribuir para a construção de uma literatura socioeconômica nacional. É assim que trabalhos de grande valor teórico são produzidos e discutidos, compondo um novo campo intelectual dentro do pensamento social brasileiro. Dentre esses pensadores podemos citar, por exemplo, Roberto Campos, Celso Furtado, Ignácio Rangel, Maria da Conceição Tavares, José Serra, Fernando Henrique Cardoso etc. A maioria desses trabalhos sofreu grande influência inicial do pensamento cepalino-estruturalista, que trouxe uma análise do processo de desenvolvimento específico da formação capitalista dos países atrasados da América Latina.

Dentre esses autores destaca-se Celso Furtado como o mais brilhante economista da primeira geração da CEPAL (Comissão Econômica para a América Latina), que constrói uma vasta obra em que dá uma formulação refinada à concepção de Raúl Prebisch sobre as relações centro-periferia e que explica o processo de industrialização dos países subdesenvolvidos da América Latina em termos do modelo de industrialização por substituição de importação, tendo sempre como referência o processo brasileiro.

No decorrer da década de 1960, há o surgimento de críticas ao pensamento cepalino motivadas, em grande medida, pela crise do modelo de industrialização por substituição de importação na América 
Latina e no Brasil, que não havia solucionado problemas históricos, tais como dependência externa, concentração de renda, desemprego, exclusão social, agravados pela inflação e estrangulamentos na infraestrutura. Parte dessas críticas surge no âmbito do próprio pensamento estruturalista - contestando as teses estagnacionistas - e tem como alguns de seus principais pensadores Maria da Conceição Tavares e José Serra, que são intelectuais brasileiros da segunda geração da CEPAL. Temos também, neste período, o surgimento de teses que serão a base para a construção do que virá a ser a Teoria da Dependência, cujos maiores expoentes são Fernando Henrique Cardoso e Enzo Faletto. Além dessas duas vertentes, ganham expressão as análises de alguns pensadores influenciados pelas formulações marxistas, dentre os quais podemos citar Ignácio Rangel, Theotônio dos Santos e Rui Mauro Marini.

Em meio a esse complexo processo, surge na década de 1970, a produção teórica de um membro do CEBRAP (Centro Brasileiro de Análise e Planejamento) que, ao longo de sua formação, sofreu influências do estruturalismo-cepalino e do pensamento marxista. Tratase de Francisco de Oliveira que apresenta uma nova leitura das formas de acumulação capitalista no Brasil sob uma vertente marxista, fazendo crítica ao pensamento dualista da CEPAL e tornando-se um importante interlocutor das análises cepalinas e furtadianas no Brasil.

A forma de interpretação utilizada por Francisco de Oliveira foi fortemente influenciada pelas teses da teoria da dependência que também não isolavam os fatores sociais, políticos e econômicos. Na realidade, Francisco de Oliveira, para construir sua análise da economia brasileira, apropriou-se de algumas formulações dos teóricos da dependência somando-as com suas interpretações de origem marxista. 


\section{Breve introdução ao pensamento cepalino Furtadiano}

A CEPAL foi uma instituição criada pela ONU (Organização das Nações Unidas) no ano de 1948, com o objetivo de analisar especificamente as tendências econômicas e sociais do desenvolvimento capitalista latino-americano, além de propor políticas de superação do subdesenvolvimento.

Composta por economistas latino-americanos, a CEPAL contribuiu significativamente para o entendimento do sistema capitalista na região “periférica”. Seu principal teórico foi Raúl Prebisch, formulador das diretrizes básicas do pensamento cepalino, auxiliado por outros intelectuais, dentre os quais se destacaram: Celso Furtado, José Medina Echavarría, Aníbal Pinto, entre outros. (BIELSCHOWSKY, 1998, p. 39).

A CEPAL teorizou sobre o subdesenvolvimento latino-americano, afirmando que esse não era uma etapa necessária no processo de evolução das economias capitalistas e, analisando as estruturas econômicas dos países periféricos, afirmava que essas estruturas eram um entrave ao desenvolvimento industrial e impediam que os países latinoamericanos superassem a condição de países atrasados e subordinados no cenário capitalista mundial.

Segundo a teoria cepalina, a geração de desigualdade era inerente ao processo de desenvolvimento capitalista mundial, pois os países centrais absorviam parte dos frutos do progresso técnico gerado nos países periféricos. Com isso, estes últimos se perpetuariam em uma condição atrasada e subordinada no cenário capitalista global. (Prebisch, 1998, p. 83).

[...] Na CEPAL a “condição periférica” era interpretada como de- 
terminante de problemas a serem superados por políticas econômicas e sociais bem orquestradas, a nível nacional e internacional, ou seja, não significava fonte de exploração insuperável que implicasse necessidade de ruptura como o capitalismo. (BIELSCHOWSKY, 1998, p. 39).

Como relata Ricardo Bielschowsky, a “condição periférica” poderia ser superada, com um projeto de reforma executado pelo Estado, mesmo dentro da lógica de reprodução do sistema capitalista, logo, não se tratava de propor uma ruptura com o capitalismo.

Como forma de superação dessa condição, os teóricos cepalinos afirmavam que os países periféricos deveriam executar profundas reformas - agrária, tributária, financeira - com o objetivo de transformar sua estrutura econômica com o objetivo de incentivar o processo de industrialização. Isto é, para os cepalinos, a industrialização era uma ferramenta de superação do subdesenvolvimento (BIELSCHOWSKY, 1998, p. 43).

Dentre os pensadores cepalinos no Brasil, podemos dizer que Celso Furtado foi o maior expoente, uma vez que aplicou o arsenal teórico cepalino para compreender a realidade econômica brasileira e propor um projeto de desenvolvimento nacional (BIELSCHOWSKY, 1998, p. 22).

Celso Furtado afirmava que as características estruturais internas brasileiras eram antagônicas ao desenvolvimento econômico nacional e, para superar a condição de economia subdesenvolvida, o Estado deveria formular políticas de incentivo à industrialização no Brasil (FURTADO, 1972, p. 241).

Segundo Furtado, o Estado deveria manter uma política contrária à concentração de terras e à criação de latifúndios, uma vez que a existência desses fatores prejudicava o aumento da produtividade, além de serem um dos maiores empecilhos à permanência do trabalhador ru- 
ral no campo. Para o autor, estes trabalhadores estavam presos a uma lógica produtiva que não lhes permitia progredir, fazendo com que migrassem para os centros urbanos em busca de trabalho e melhores condições de vida. Esse excesso de mão de obra ociosa nos centros urbanos barateava a remuneração dos trabalhadores, pressionando os salários negativamente (FURTADO, 1972, p. 242).

Celso Furtado afirmava que essa tendência ao rebaixamento dos salários tornava-se um dos principais fatores que impedia o Brasil de conservar os frutos de seu próprio progresso técnico, pois ao reduzir os salários pagos para a população, além de dificultar que essa população absorva o excedente produtivo dos demais países, barateava os preços dos produtos primários em relação aos produtos industriais. Isto é, para Furtado, a coexistência de setores com estruturas arcaicas e modernas dificultavam o desenvolvimento capitalista brasileiro.

Quando descreveu o processo de industrialização brasileiro, Furtado afirmava que este ocorreu através do chamando modelo de industrialização por substituição de importações. Segundo ele, em linhas gerais, a atividade industrial brasileira iniciou-se produzindo bens que anteriormente eram importados. O estímulo a essa produção interna ocorreu devido a dificuldades externas para importação. Assim sendo, os choques externos incentivaram os setores internos da economia brasileira a substituírem os produtos antes importados. Furtado afirmava que esse movimento deslocou o centro dinâmico da economia, até então agrário e exportador, para o urbano e industrial, baseado no desenvolvimento das atividades ligadas ao mercado interno (FURTADO, 1972, p. 222).

Segundo o autor, o processo de desenvolvimento industrial brasileiro foi espontâneo, estimulado por adversidades externas, sem participação ativa do Estado. Segundo Furtado, a implantação da política 
de desvalorização cambial atendeu ao setor cafeeiro, porém, essa desvalorização do câmbio somada com as dificuldades de importação, teve como consequência involuntária o desenvolvimento do processo de industrialização brasileiro (FURTADO, 1972, p. 193).

Para Celso Furtado, o modelo de industrialização substitutiva possuía limitações e uma tendência à estagnação. Segundo o autor, após a primeira fase deste processo em que as atividades industriais substituíam os bens de consumo não duráveis, viria uma segunda fase em que seria necessário a substituição de bens de consumo duráveis e de bens de capital (FURTADO, 1968).

Nessa segunda fase do processo substitutivo, as empresas de bens de capital, por possuírem um mercado relativamente restrito, somente teriam condições de desenvolverem suas atividades com os preços em níveis extremamente elevados. Essa elevação nos preços dos equipamentos tenderia a reduzir a taxa de lucro dos demais setores e, para anular essa tendência, foram utilizadas tecnologias importadas poupadoras de mão de obra. Essas tecnologias geraram uma maior concentração de renda ao passo que reduziram o nível de emprego da economia (FURTADO, 1968).

Segundo Celso Furtado, o desencadeamento desse processo levaria à estagnação econômica, uma vez que, ocorrendo uma elevação nos preços dos equipamentos que poupam mão de obra, a quantidade necessária de capital despendido para aquisição dos mesmos aumentaria. Portanto, para manter a taxa de lucro, os industriais necessitariam repassar os novos custos. Na medida em que esses equipamentos geravam uma redução no nível de emprego e consequentemente da renda, existiria uma redução no consumo, o que não permitia um repasse de custo ainda maior por parte dos industriais. Isto é, para Furtado, a tendência à estagnação surge através da incapacidade de consumo 
dos bens industriais devido à pressão exercida na renda por meio dos equipamentos poupadores de mão de obra (FURTADO, 1968).

\section{Francisco de Oliveira e a crítica ao pensamento cepalino Furtadiano}

O trabalho de Francisco de Oliveira intitulado A Economia Brasileira: crítica à razão dualista foi publicado pela primeira vez em Estudos Cebrap, n ${ }^{\circ} 2$ no ano de 1972. Somente em 1981 foi transformado em livro. Vivíamos em plena ditadura militar comandada pelo General Médici, período conhecido como "os anos de chumbo da ditadura”. A repressão e a censura se intensificavam, dificultando a publicação de trabalhos que tinham por objetivo analisar a realidade brasileira. Em meio a esse processo, o ensaio de Oliveira teve considerável importância quando, escapando da censura, se transformou em mais um importante trabalho produzido no CEBRAP. Influenciou diversos estudantes e intelectuais que, desde logo, passaram a discutir as teses levantadas por Francisco de Oliveira.

Embora tenha a teoria cepalina como principal objeto de discussão, o autor também se opôs de maneira arriscada às políticas econômicas e sociais adotadas pelo governo militar. Francisco de Oliveira, neste momento já apresentava ao público seu “perfil quixotesco" - expressão utilizada por Roberto Schwarz (2003) - e se refere aos economistas do governo militar como os “sem razão", atribuindo a eles grande parte dos problemas brasileiros.

É absolutamente necessário notar que, mesmo contestando os principais argumentos cepalinos, esta análise não pretendia negar as contribuições teóricas da CEPAL para o desenvolvimento da Ciência Econômica latino-americana. Segundo Francisco de Oliveira, as teorias 
oriundas do "modelo CEPAL" eram as únicas que permitiam uma interlocução. Dessa forma, o autor fazia uma dura crítica aos economistas conservadores brasileiros, que mesmo não tendo produzido nenhuma teoria plausível, faziam oposição às análises construídas pela CEPAL.

O esforço reinterpretativo que se tenta neste trabalho suporta-se teórica e metodologicamente em terreno completamente oposto ao do dual-estruturalismo: não se trata, em absoluto, de negar o imenso aporte de conhecimento bebido diretamente ou inspirado no "modelo CEPAL", mas exatamente de reconhecer nele o único interlocutor válido, que ao longo dos últimos decênios contribuiu para o debate e a criação intelectual sobre a economia e a sociedade brasileira e latino-americana. Mesmo porque a oposição ao "modelo CEPAL", no período assinalado, não se fez nem se deu em nome de uma postura teórica mais adequada [...] Como pobres papagaios, limitaramse durante décadas a repetir os esquemas aprendidos nas universidades anglo-saxônicas sem nenhuma perspectiva crítica, sendo rigorosamente nulos seus aportes à teoria da sociedade latino-americana. Assim, ao tentar-se uma "crítica à razão dualista”, reconhece-se a impossibilidade de uma crítica semelhante aos "sem razão". (OLIVEIRA, 2003a, p. 32)

Podemos dizer que Francisco de Oliveira, para produzir sua crítica ao pensamento dualista cepalino, se apegou a três elementos fundamentais: primeiro, a importância que os setores atrasados desempenhavam para a expansão dos setores modernos, dentro da dinâmica de evolução do sistema capitalista; segundo, a função exercida pelo Estado no processo de industrialização brasileiro; terceiro, a importância que as relações sociais e econômicas internas tiveram para facilitar o processo de acumulação capitalista nacional.

[...] Ao fazer a "crítica à razão dualista", ao mostrar a simbiose do "arcaico" e "moderno" do formal e do informal e o modo como essas relações eram tecidas, postas e repostas na lógica mesma da acumu- 
lação capitalista, Chico definia um outro plano de referência que projetava as figuras do "atraso" - a urbanização caótica, o terciário inchado, a economia de subsistência e o cada vez mais amplificado universo do trabalho informal, a pobreza que se espalha por todos os lados - no centro da mesma moderna economia urbana. [...]. (BAVA, 2006, p. 184).

Francisco de Oliveira afirmava que o modo de produção subdesenvolvido, que pressupõe a existência de setores atrasados e modernos, tal como os teóricos dualistas formulavam, sempre existiu em diversos sistemas e em quase todos os períodos de desenvolvimento. Para o autor, o subdesenvolvimento latino-americano era uma produção do próprio sistema capitalista que se utilizou das economias préindustriais da América Latina como reserva de acumulação primitiva (OLIVEIRA, 2003a, p. 32).

Segundo Oliveira, os teóricos do subdesenvolvimento não analisavam as relações sociais e econômicas internas, tratando o problema do subdesenvolvimento apenas sob a ótica das relações externas. Assim, para o autor, o arsenal teórico cepalino contribuiu para a ausência de teorias mais complexas referentes ao capitalismo brasileiro. Segundo ele, todas as análises subsequentes não conseguiram superar as conclusões cepalinas e, para que essa superação fosse possível, se fazia necessário uma crítica radical ao processo de expansão capitalista em curso, assim como às teorias que pretendiam descrever este processo (OLIVEIRA, 2003a, p. 34).

\section{Arcaicos e modernos: dualidade ou dialética?}

Uma das principais críticas que Francisco de Oliveira fez ao pensamento cepalino furtadiano refere-se à função que os setores arcaicos desempenharam para a expansão do sistema capitalista brasileiro, 
principalmente com relação ao setor agrário e ao setor terciário.

No que se refere ao setor agrário, Oliveira afirmava que a agricultura manteve sua característica primitiva e concentradora de renda e embora tenha deixado de ser o setor prioritário no cenário de desenvolvimento nacional, teve grande importância no desencadear do processo industrial. Uma estrutura agrária primitiva, na sua visão, facilitava a acumulação capitalista de duas formas: primeiro por fornecer mão de obra excedente, que gerava um exército industrial de reserva e auxiliava no rebaixamento dos níveis salariais, segundo, por baratear os produtos que compunham a cesta do trabalhador, reduzindo os custos da reprodução da força de trabalho e facilitando a acumulação capitalista (OLIVEIRA, 2003a, p. 42).

Assim, não é simples o fato de que, em termos de produtividade, os dois setores - agricultura e indústria - estejam distanciando-se, que autoriza a construção de um modelo dual; por detrás dessa aparente dualidade, existe uma integração dialética. (OLIVEIRA, 2003a, p. 47).

Como mostra o fragmento acima, para Francisco de Oliveira não havia uma relação oposta entre o polo “moderno" e o “arcaico”. Na lógica do desenvolvimento capitalista, esses polos interagiam e permitiam o avanço do sistema. Dessa forma, Oliveira se contrapõe ao pensamento furtadiano, que afirmava que a coexistência de setores “modernos” e “arcaicos” era antagônica ao processo de desenvolvimento capitalista nacional.

Quando descrevia o processo de industrialização brasileiro, o autor mais uma vez contestava a tese furtadiana quando contrariava a ideia de que a industrialização brasileira era restringida pela falta do mercado consumidor rural. Segundo Oliveira, a industrialização nunca precisou do mercado rural para se desenvolver. A indústria sempre 
focou seu desenvolvimento no plano urbano.

Francisco de Oliveira ressaltava que embora a agricultura tenha sofrido com as políticas de mudança para o "novo" modelo, foi recompensada pela permissão em manter sua característica "primitiva" de grande exploração da força de trabalho rural.

Quando trabalhou a questão do setor terciário, o autor foi incisivo em contrariar a teoria cepalina-furtadiana que afirmava que o setor terciário era “inchado". Para o autor, o crescimento do setor terciário fazia parte da expansão capitalista brasileira na medida em que absorvia cada vez mais a força de trabalho. Este setor estava inserido de maneira dinâmica na lógica de acumulação capitalista e contribuiu para acentuar a má distribuição de renda no Brasil. Vale dizer que no setor terciário, os níveis salariais baixíssimos permitiam a transferência de parte da mais-valia ao setor produtivo.

A expansão do capitalismo no Brasil se dá introduzindo relações novas no arcaico e reproduzindo relações arcaicas no novo, um modo de compatibilizar a acumulação global, em que a introdução das relações novas no arcaico libera força de trabalho que suporta a acumulação industrial-urbana e em que a reprodução de relações arcaicas no novo preserva o potencial de acumulação liberado exclusivamente para os fins de expansão do próprio novo. (OLIVEIRA, 2003a, p. 60).

Ainda com relação ao setor terciário, Francisco de Oliveira dizia que era possível perceber uma evolução dos serviços com um grau de capitalização muito pequeno, que na verdade, utilizava-se da grande oferta de força de trabalho a preços demasiadamente baixos. Esses serviços fornecidos à população de baixa renda beneficiavam, no limite, as grandes unidades capitalistas. Segundo Oliveira, essa foi mais uma forma que a evolução do capitalismo no Brasil utilizou, aumentando ainda mais a acumulação e a concentração de renda. Isto é, o capita- 
lismo no Brasil se utilizou de uma periferia não capitalista para seu desenvolvimento.

Francisco de Oliveira afirmava que o crescimento econômico brasileiro é consequência da expansão capitalista, porém, esse desenvolvimento possuía algumas características específicas que certamente se diferenciavam do modo clássico de desenvolvimento capitalista.

[...] A “especificidade particular” de um tal modelo consistiria em reproduzir e criar uma larga "periferia" onde predominam padrões não-capitalísticos de relações de produção, como forma e meio de sustentação e alimentação do crescimento dos setores estratégicos nitidamente capitalistas, que são a longo prazo a garantia das estruturas de dominação e reprodução do sistema. (OLIVEIRA, 2003a, p. 69).

A citada "especificidade particular" do desenvolvimento brasileiro é, portanto, justamente a coexistência de dois modos de acumulação aparentemente opostos, isto é, o modo “primitivo”, baseado na estrutura primário-exportadora; e o modo “moderno”, baseado na acumulação capitalista pela ótica da industrialização. Ao contrário do modelo clássico, onde o antigo modo de produção era um obstáculo para o desenvolvimento do "moderno", e logo precisava ser destruído, no caso brasileiro, segundo Oliveira, não havia a exigência da destruição do antigo modo de acumulação e sim uma coexistência entre esses dois polos:

Ao contrário do modelo "clássico", que necessitava absorver sua "periferia” de relações de produção, o esquema num país como o Brasil necessitava criar sua "periferia”. (OLIVEIRA, 2003a, p. 66).

Percebemos que Francisco de Oliveira se utiliza da teoria marxista de desenvolvimento desigual e combinado para explicar o processo de desenvolvimento capitalista brasileiro. Na realidade, Oliveira se apropria, em parte, das formulações marxistas desenvolvidas por Leon 
Trotsky - que teoriza esse processo considerando a história da Rússia (TROTSKY, 1967). Na leitura de Oliveira, o sistema capitalista gerava desigualdades que eram necessárias para a sua própria expansão. $\mathrm{O}$ autor nega uma dualidade entre os setores atrasados e modernos e procura elucidar suas verdadeiras funções no processo do desenvolvimento capitalista brasileiro.

$\mathrm{Na}$ verdade, o cerne da crítica de Oliveira ao pensamento cepalino encontrava-se na forma como se concebia o processo de desenvolvimento capitalista mundial. Para os cepalinos o desenvolvimento capitalista gera desigualdades que devem ser superadas. $\mathrm{O}$ autor demonstra que essas desigualdades fazem parte do movimento de expansão capitalista e que ela é utilizada como ferramenta para permitir a acumulação de capital. Assim, enquanto para os cepalinos esse movimento era somente desigual, para Oliveira, o desenvolvimento capitalista era desigual e combinado.

\section{Industrialização substitutiva: espontânea ou induzida?}

Outra crítica feita por Francisco de Oliveira ao pensamento furtadiano está relacionada ao modo como estes autores descreviam o processo de industrialização no Brasil. Segundo Oliveira, os teóricos cepalinos não consideraram a participação que o Estado exerceu neste processo e explicaram o desencadeamento da industrialização considerando somente as mudanças nas relações externas.

Com o intuito de desenvolver a sua interpretação do processo de industrialização brasileiro, Oliveira inicia sua análise destacando a importância que a Revolução de 1930 teve para no processo de alteração da estrutura econômica brasileira de agrário-exportadora para urbano- 
industrial. Segundo Oliveira, no centro das transformações econômicas, tínhamos o Estado como um fator fundamental no desenvolvimento capitalista, estabelecendo políticas de desenvolvimento e regulamentando as relações internas de produção.

Segundo Oliveira (2003a, p. 38), a legislação trabalhista criada por Getúlio Vargas regulamentou a relação capital-trabalho, gerando condições para o desenvolvimento capitalista brasileiro, uma vez que nivelou pela base o nível de salários da economia. Esse salário mínimo igualava a remuneração dos trabalhadores das mais diversas categorias a um fator comum, o que facilitava a acumulação capitalista. Dessa forma, podemos dizer que, na sua interpretação, os salários foram equalizados pela base e o resultado dessa equalização foi a intensificação da acumulação capitalista no Brasil.

Como Oliveira discutiu de forma inovadora, a criação da CLT resultou na estruturação do mercado de trabalho no Brasil, ao estipular os padrões que viabilizaram o cálculo empresarial e ao fomentar a formação de um amplo exército industrial de reserva. (BELLO, 2006, p. 80).

Para Oliveira (2003, p. 38), outra considerável influência exercida pelo Estado foi, além de regulamentar a relação capital-trabalho, intervir na economia com uma política de planejamento que tinha como objetivo permitir a mudança do padrão de acumulação capitalista brasileiro. Assim, o Estado passava a investir em infraestrutura e implantar políticas cambiais que facilitavam as importações de equipamentos utilizados pelas indústrias e, consequentemente, impulsionavam a industrialização brasileira.

Assim, Oliveira era crítico no que concerne à afirmação furtadiana de que os choques externos geravam as condições internas necessárias para o surgimento da industrialização. Para ele, embora essa conclu- 
são fosse parcialmente correta, já que a crise nas relações externas realmente incentivava a produção interna, não poderíamos considerar essa característica como o único fator motivador. Para Francisco de Oliveira, o desenvolvimento capitalista brasileiro não poderia ser explicado somente do ponto de vista das relações externas. Segundo o autor, deveríamos considerar também, e principalmente, as condições internas criadas pelo populismo, que teria sido a forma política que permitiu o desenvolvimento do capitalismo no Brasil (OLIVEIRA, 2003a, p. 64).

Francisco de Oliveira (2003a, p. 65) dizia que foi esse "pacto estrutural”, permitido pelas políticas populistas, que facilitou a acumulação capitalista brasileira. Segundo o autor, as políticas populistas não transformaram as estruturas agrárias - utilizando-as de ferramenta de acumulação primitiva - além de incentivarem a industrialização através da regulamentação das relações capital-trabalho mantendo os salários a níveis baixos.

Dessa forma, Francisco de Oliveira contrariava o "espontaneísmo” apresentado nas obras clássicas de Celso Furtado, que interpretavam a industrialização brasileira através do modelo de industrialização por substituição de importações. Segundo o autor, esse processo de desenvolvimento capitalista brasileiro não foi espontâneo como afirmava Furtado e contou com forte presença de um Estado atuante que tinha a industrialização como o objetivo principal. Vale dizer que, no cenário capitalista internacional, o Brasil ainda era visto como um país subordinado na divisão internacional do trabalho e que o interesse por parte dos países centrais em desenvolver a industrialização no Brasil era irrisório (OLIVEIRA, 2003a, p. 72).

Oliveira afirmava, ao descrever o processo de industrialização intensificado durante o governo de Juscelino Kubistschek (1955-1960), 
que o Estado brasileiro não se preocupou em implementar políticas tecnológicas nacionais conjuntamente ao capital industrial nacional. Houve importação de tecnologia avançada utilizando o capital externo, o que produziu um grande salto de produtividade. A internalização de tecnologia e de capital externo intensificou a acumulação capitalista e permitiu o desenvolvimento da industrialização brasileira (OLIVEIRA, 2003a, p. 75).

Francisco de Oliveira contestava incisivamente os economistas brasileiros que não percebiam que o insistente aumento na taxa de exploração da força de trabalho foi outro fator que permitiu acumulação capitalista. Esse fato fica claro, segundo ele, quando analisamos o comportamento do salário mínimo real, que se desvalorizava ao longo das décadas de 1940, 50 e 60:

[...] a conclusão de que a característica geral do período é a de aumento da taxa de exploração do trabalho, a qual foi contra-arrestada apenas quando o poder político dos trabalhadores pesou decisivamente. Em outras palavras, seria ingênuo pensar, como o fazem os adeptos da "teoria do bolo", que os trabalhadores devem primeiro esperar que o "bolo" cresça para reivindicar melhor fatia: nos 25 anos decorridos o "bolo", isto é, o produto bruto, cresceu sempre, interrompido apenas pela recessão 1962-1966, enquanto a fatia dos trabalhadores decrescia. (OLIVEIRA, 2003a, p. 80).

Demonstrando empiricamente seu argumento, Oliveira relata que em torno de 33\% dos trabalhadores urbanos brasileiros recebiam remuneração de aproximadamente um salário mínimo. Esse número ficava ainda mais assustador quando verificávamos que em torno de 75\% dos empregados brasileiros recebiam até dois salários mínimos (OLIVEIRA, 2003a, p. 80).

Dessa forma, fica evidente a demonstração de que a institucionalização do salário mínimo facilitou a acumulação capitalista, uma vez 
que, previamente determinado, tornou-se a “obrigação máxima” das empresas.

Outro argumento que Oliveira utilizava para justificar sua tese era o fato de que, enquanto os salários reais declinavam e o custo da reprodução da força de trabalho aumentava, a industrialização brasileira encontrava-se em crescente expansão. Ou seja, o aumento da taxa de crescimento da indústria ocorria ao mesmo tempo em que a taxa de exploração da força de trabalho aumentava, intensificando a acumulação capitalista (OLIVEIRA, 2003a, p. 83).

[...] Oliveira nos brindou com alguns brilhantes “insights” sobre aquele processo, como por exemplo aqueles relacionados à importância crucial da fixação do salário mínimo para a acumulação urbana industrial, sobre os efeitos desta última em termos da estrutura de emprego urbana e, principalmente, sobre a ênfase analítica, ao menos na primeira parte de seu trabalho, não do lado da demanda mas no da oferta [...]. (MALAN e PEREIRA, 1973, p. 143).

Conforme relatado por Pedro Malan e José Pereira, a constatação feita por Francisco de Oliveira da importância que a fixação dos salários teve para o processo de acumulação capitalista brasileiro foi uma brilhante contribuição. Vale dizer que, neste ponto, se evidencia uma diferença crucial entre a análise de Oliveira e a análise de origem cepalina. Isto é, enquanto os teóricos cepalinos, inclusive Furtado, analisavam o processo de industrialização prioritariamente pela ótica do consumo, considerando os níveis de renda e a capacidade de realização do consumo; a análise produzida por Francisco de Oliveira se orienta pela ótica da produção, enfatizando os aspectos da acumulação e reprodução do capital dentro da esfera produtiva.

Como vimos, para Oliveira, a passagem de um modelo capitalista primitivo para um modelo capitalista moderno, baseado na acumulação sobre a empresa industrial, utilizou-se de vários fatores internos 
com forte influência do Estado. Assim, a descrição desse processo não poderia se restringir à análise simplista de cunho cepalino, como é o caso do modelo de industrialização por substituição de importação.

\section{Industrialização substitutiva e o estagnacionismo}

A terceira crítica importante produzida por Oliveira aos argumentos cepalinos-furtadiano está relacionada à tese de que a industrialização substitutiva tenderia à estagnação. Conforme demonstrado no início deste trabalho, com a evolução do processo de industrialização, as empresas capitalistas, com o objetivo de manter suas taxas de lucro, aumentariam a quantidade de equipamentos poupadores de mão de obra. Com isso, se reduziria o nível geral de emprego e renda na economia, dificultando o consumo e reduzindo a atividade econômica no mercado interno.

Segundo Oliveira (2003a, p. 49), o equívoco da conclusão furtadiana, mesmo descrevendo o processo corretamente, foi não considerar o processo de formação de mais-valia, isto é, o comportamento do sistema permitia o aumento da mais-valia relativa e até mesmo da maisvalia absoluta, o que garantia a acumulação através da exploração da força de trabalho.

Percebemos que Francisco de Oliveira novamente se apropria da teoria marxista para analisar criticamente a tese de estagnacionismo, desenvolvida por Celso Furtado. Na realidade, uma crítica a essa tese já tinha sido feita por Maria da Conceição Tavares e José Serra, porém, essa crítica ainda se situava dentro do terreno cepalino.

Francisco de Oliveira também contestou a tese defendida por Tavares e Serra, que afirmavam que a crise pré-64 foi consequência da re- 
dução das inversões que eram dificultadas pela falta de financiamento e pelo aumento dos salários (TAVARES e SERRA, 2000, p. 589). Oliveira discordava dessa afirmação usando como referência as condições políticas que desencadearam o golpe de 64. Segundo o autor, a análise de Tavares e Serra era "economicista”, ou seja, ignorava os fatos políticos e sociais existentes no início da década de 1960. Na sua interpretação, “a inversão cai não porque não pudesse realizar-se economicamente, mas sim porque não poderia realizar-se institucionalmente.” (OLIVEIRA, 2003a, p. 92). Isto é, considerando as mudanças no cenário político brasileiro, em que os trabalhadores passaram a intervir na política de maneira mais ativa, percebia-se uma ineficácia do Estado como mediador dos conflitos políticos, diminuindo seu poder de intervir e institucionalizar as relações de produção.

Oliveira afirmava, ao contrário do que dizia Celso Furtado e os demais teóricos cepalinos, que a concentração de renda não era obstáculo ao crescimento da economia. Na verdade, conforme mostrava a pesquisa de João Carlos Duarte (1971), citada por Oliveira, a economia continuava crescendo, apoiando-se propriamente na desigual distribuição de renda. Essa observação contestava firmemente os argumentos de Tavares e Serra intitulada “redistribuição intermediária”.

[...] o mercado para os produtos industriais dos novos ramos assentava-se exatamente numa distribuição extremamente desigualitária da renda, a qual estava muito longe de constituir-se em obstáculo ao crescimento, como supõe Furtado e todos os seguidores do dualestruturalismo cepalino. (OLIVEIRA, 2003a, p. 96).

Estes autores, definindo o processo de redistribuição intermediária, afirmavam que houve um acréscimo de renda da classe média e uma correspondente redução nos salários da classe de renda baixa, o que aumentaria o poder de compra da classe média tornando-a capaz 
de adquirir bens de consumo duráveis (TAVARES \& SERRA, 2000, p. 589).

Em entrevista concedida aos organizadores do livro Conversas com Economistas Brasileiros II (1999), Francisco de Oliveira comenta a esse respeito:

[...] A Maria da Conceição e José Serra, no "Além da Estagnação", no meu modo de ver, incorrem no equívoco de pensar que a distribuição de renda orientou o consumo. Sem pensar que a distribuição de renda é produzida pelo processo de acumulação de capital. (OLIVEIRA, In: MANTEGA e REGO, 1999, p. 108).

Francisco de Oliveira não discordava de que a classe média tivesse se beneficiado do crescimento ocorrido no início da década de 1960, porém, afirmava que a redistribuição intermediária não era possível, uma vez que não havia relações de produção entre a classe baixa e a classe média. Além disso, aumentar a renda da classe média significava reduzir a taxa de lucro e, consequentemente, dificultaria a acumulação e a expansão capitalista. O que se mostrou na prática, segundo o autor, foi a intensificação da concentração de renda e a expansão considerável da acumulação capitalista (OLIVEIRA, 2003a, p. 100).

Para Oliveira, o governo passou a executar políticas de condução econômica como, por exemplo, subsídios às exportações de excedentes não consumidos e os incentivos aos investimentos industriais, com o claro objetivo de manter as altas taxas de lucro. Dessa forma, Francisco de Oliveira dizia que no pós-64 o sistema permanecia caminhando no sentido de concentrar renda e utilizando-se da exploração do trabalho como ferramenta para a sustentação da acumulação, permitindo assim, a manutenção da taxa de lucro capitalista (OLIVEIRA, 2003a, p. 104).

Segundo Oliveira, as consequências da concentração de renda 
para o desenvolvimento brasileiro eram pouco debatidas, sendo que as discussões existentes tinham um caráter ideológico muito intenso, não trazendo resultados consideráveis ${ }^{1}$ (OLIVEIRA, 2003a, p. 107).

Como a produção de desigualdade é intrínseca ao sistema capitalista, segundo Oliveira, só existiam dois meios pelos quais essa tendência poderia ser revertida. A primeira delas seria a escassez de mão de obra e a segunda seria a organização das classes trabalhadoras. No Brasil, não existiam nenhuma dessas condições, possuíamos uma larga oferta de força de trabalho, que foi intensificada pela própria especificidade particular do capitalismo brasileiro - ao utilizar tecnologias poupadoras de mão de obra (OLIVEIRA, 2003a, p. 112).

Quanto à organização das classes trabalhadoras, era evidente que no período pós-64 as entidades que representavam os trabalhadores, isto é, os sindicatos, possuíam um insignificante poder de barganha e praticamente nenhuma autonomia política, uma vez que ficavam subordinados a decisões da política econômica do governo, que estabelecia, de acordo com seus interesses, os índices de reajuste salarial (OLIVEIRA, 2003a, p. 113).

No entanto, mesmo demonstrando que a concentração de renda no processo de acumulação capitalista brasileiro não foi um empecilho para sua expansão, Oliveira concordava que essa concentração

1. Francisco de Oliveira cita um estudo feito por Simon Kuznets que analisou o processo de expansão capitalista nos países centrais. Kuznets afirmava que inicialmente esse processo gerou desigualdades, porém, a partir de um determinado estágio de evolução, começou a existir um processo de diminuição das desigualdades que propiciou maior dinamismo ao sistema. Segundo o próprio Kuznets, o sistema capitalista não possuía propriamente nenhum mecanismo automático que permitia esse processo de distribuição e a permanente tendência à concentração de renda era intrínseca ao sistema capitalista. Kuznets explica que o processo de redistribuição historicamente só foi possível, através da organização da classe trabalhadora que coibia o excesso de exploração da força de trabalho (OLIVEIRA, 2003a, p. 109). Para maiores detalhes desse trabalho, ver Kuznets (1970). 
prejudicava os setores "tradicionais" que dependiam do consumo dos estratos de baixa renda. A sobrevivência desse setor só foi possível, no seu entender, devido às políticas de subsídio à exportação, implementadas pelo governo pós-64. Dessa forma, todo o excedente não consumido internamente seria exportado, processo denominado por Oliveira de esterilização de excedente (OLIVEIRA, 2003a, p. 114).

Dessa forma, Oliveira afirmava que a manutenção do processo de concentração de renda, que gerava desigualdades, só prejudicava a expansão do sistema capitalista nos casos clássicos. No caso brasileiro, essa exclusão, que intensificou no período pós-64, reafirmouse como característica essencial para o dinamismo do sistema (OLIVEIRA, 2003a, p. 118).

Uma leitura mais atenta da Crítica, no entanto, mostra que sua tese é que as contradições fundamentais do Brasil não foram superadas em 1964. Esta, para o autor, não é uma nova revolução burguesa como a de 1930. Mas uma contra-revolução, cujos horizontes históricos estavam, já no início dos anos 1970, saturados de contradições e limites. (GUIMARÃES, 2006, p. 130).

Para Oliveira, a superação dessa tendência era um processo dialético, uma vez que havia uma contradição de interesses entre as classes trabalhadoras e a burguesia capitalista. Considerando a situação política em que o Brasil se encontrava, toda contestação feita a esse processo, tendo por objetivo distribuir os ganhos de produtividade para as classes menos favorecidas, transformava-se em uma contestação ao regime e consequentemente eram repreendidas (OLIVEIRA, 2003a, p. 119). 


\section{Nordeste: uma aplicação regional da dualidade cepalina}

Como vimos acima, Francisco de Oliveira produziu uma crítica à teoria furtadiana no que se refere ao desenvolvimento da economia brasileira. Porém, da mesma forma que Celso Furtado regionalizou os conceitos cepalinos para propor um projeto de desenvolvimento do Nordeste, Oliveira também regionalizou sua crítica à proposta furtadiana. Desta forma, temos uma aplicação prática do debate nacional deslocado para o plano regional. Veremos a seguir detalhes deste instigante debate teórico envolvendo estes dois grandes intelectuais brasileiros.

Quando se propôs a analisar as relações inter-regionais brasileiras, Celso Furtado valeu-se mais uma vez de sua análise dualista de origem cepalina. Furtado dividiu o cenário nacional em dois polos, as regiões centrais e periféricas. Para o autor, a região Centro-Sul era a maior beneficiada nas relações de troca mantida com as demais regiões brasileiras, principalmente com a região Nordeste, local em que se verificava maior existência de desigualdade social e econômica (FURTADO, 1979).

Dessa forma, Celso Furtado defendia um plano de desenvolvimento industrial no Nordeste que permitiria a superação dos problemas estruturais daquela região. Segundo ele, para que isso fosse possível, seria necessária uma ação planejada do Estado (FURTADO, 1979).

Francisco de Oliveira também produziu trabalhos que se relacionam com a questão nordestina e que foram de grande importância para o desenvolvimento da produção teórica que tinha como tema a questão regional brasileira. Ainda durante a década de 1970, esses trabalhos 
colocaram em discussão as interpretações correntes em relação às desigualdades regionais brasileiras e, a partir de então, abriram caminho para um novo modo de interpretação da realidade regional nacional. Como coloca Vieira:

É importante que se lembre, agora, que foi Francisco de Oliveira que, em meados dos anos 70, abriu caminho para essa leitura das questões regionais no Brasil, em termos de divisão regional do trabalho sob controle hegemônico da produção capitalista. (VIEIRA, 2007, p. 258).

O principal trabalho de Oliveira que trata da temática nordestina é o livro Elegia para uma Re(li)gião: SUDENE, Nordeste, Planejamento e conflitos de classes (1977). Nesse trabalho, o autor traz uma nova interpretação do Nordeste brasileiro, considerando conjuntamente os fatores históricos, econômicos, sociais e políticos que teriam influenciado como um todo o processo de construção do sistema capitalista nacional. Assim sendo, Francisco de Oliveira, mais uma vez recusa a análise econômica isolada, assim como fez na Crítica à Razão Dualista, e trata a questão Nordeste de maneira ampla, considerando toda a sua complexidade.

[...] Francisco de Oliveira tornou-se, seguramente, o mais consistente interlocutor crítico das teses dualistas de Furtado, que, seguindo a tradição do pensamento cepalino, trata a questão regional sob o enfoque dos "desequilíbrios regionais" e a intervenção planificadora do Estado em termos da realocação dos "fatores de produção", para um nível ótimo, com vistas ao desenvolvimento econômico regional. (VIEIRA, 2007, p. 258).

O método de interpretação utilizado por Francisco de Oliveira difere da ótica utilizada por Celso Furtado que, como mencionado, se baseava nas formulações de origem estruturalista cepalina. Conforme 
relata Vieira, os teóricos cepalinos interpretavam a questão do desenvolvimento regional nordestino através da ótica dos “desequilíbrios regionais”, e isso pressupunha a existência de uma dualidade entre as “regiões” brasileiras. Nas palavras do próprio Celso Furtado:

Não podem coexistir, no mesmo país, um sistema industrial de base regional e um conjunto de economias primárias dependentes e subordinadas, por uma razão muito simples: as relações econômicas entre uma economia industrial e economias primárias tendem sempre a formas de exploração. (FURTADO, 1959, p. 16).

Francisco de Oliveira discorda deste modo de interpretação, dando início a uma análise da questão do Nordeste utilizando o conceito de divisão regional do trabalho e considerando o padrão de acumulação capitalista nacional. O autor insere em sua análise os conflitos sociais e as contradições geradas pela expansão do capitalismo no Brasil que, inevitavelmente, desencadeavam um desenvolvimento inter-regional desigual. Mais uma vez Francisco de Oliveira se vale do pensamento marxista para entender a realidade socioeconômica nacional e produzir uma crítica ao projeto de desenvolvimento do Nordeste proposto pela SUDENE (OLIVEIRA, 1977, p. 25).

Segundo Oliveira, o projeto de planejamento da SUDENE para o desenvolvimento do Nordeste surge tomando como ponto de partida o aparente desequilíbrio existente entre as “regiões” Centro-Sul e Nordeste. É de fácil percepção que as formulações defendidas pela SUDENE demonstravam uma grande influência do pensamento cepalino.

Pode-se dizer que a SUDENE “regionalizou” os conceitos cepalinos e os aplicou ao plano nacional. O Centro-Sul era visto como o polo central e o Nordeste como polo periférico; as relações de troca entre esses polos seriam desiguais e beneficiavam a "região” Centro-Sul, 
fazendo com que o Nordeste se perpetuasse na condição atrasada. Em recente entrevista a Guido Mantega e José Marcio Rego, Francisco de Oliveira comenta que:

[...] A SUDENE era toda estruturada sobre o modelo da CEPAL. No Nordeste, a sua proposta de industrialização fazia as vezes da proposta de industrialização que a CEPAL fez para modificar a relação desfavorável dos termos do intercâmbio. A SUDENE é uma cópia disso [...] (OLIVEIRA In: MANTEGA e REGO, 1999, p. 100).

O projeto de desenvolvimento da SUDENE pretendia alavancar o processo de crescimento capitalista nos estados nordestinos, com o intuito de superar as desigualdades regionais existentes entre as regiões Centro-Sul e Nordeste. Para atingir esse objetivo a SUDENE procurou inserir uma política de planejamento no Nordeste acreditando que um processo de desenvolvimento, pautado sobre um projeto de industrialização, poderia trazer os melhores resultados para o desenvolvimento da "região" nordestina.

Dialogando com as formulações furtadianas adotadas pela SUDENE, Francisco de Oliveira afirmava que o planejamento não poderia ser entendido somente como na concepção estruturalista cepalina (OLIVEIRA, 1977, p. 29). Na realidade, a política de planejamento teria sido a ferramenta utilizada pelo Estado para permitir o avanço do sistema capitalista nacional. O Nordeste teria sido utilizado como área de acumulação primitiva de capital que permitiu o desenvolvimento capitalista brasileiro encabeçado pela “região” Centro-Sul. Assim sendo,

O planejamento não é, portanto, a presença de um Estado mediador, mas ao contrário, a presença de um Estado capturado ou não pelas formas mais adiantadas da reprodução do capital para forçar a passagem no rumo de uma homogeneização, ou conforme é comumente descrito pela literatura sobre planejamento regional, no rumo 
da “integração nacional”. (OLIVEIRA, 1977, p. 30).

Ao contrário das teses dualistas cepalinas que viam as diversas “regiões” em um mesmo espaço nacional com características opostas e antagônicas, Francisco de Oliveira afirmava que, mesmo possuindo um diferente modo de reprodução capitalista e uma estrutura de classe distinta, estas “regiões” estavam inclusas em um mesmo processo de desenvolvimento capitalista.

Novamente nutrindo-se da concepção marxista de desenvolvimento desigual e combinado, Oliveira defendia que a aparente contradição existente entre as regiões Centro-Sul e Nordeste faziam parte da lógica de reprodução e desenvolvimento do sistema capitalista brasileiro. Para ele havia uma divisão regional do trabalho no espaço nacional brasileiro na qual o Nordeste possuía uma função subordinada como fornecedor de mão de obra barata advinda dos migrantes nordestinos que se dirigiam para a “região” Centro-Sul (OLIVEIRA, 1977, p. 37). Esses migrantes formavam o exército industrial de reserva, isto é, geravam um excedente de força de trabalho ociosa que mantinha os salários baixos permitindo a acumulação capitalista no Centro-Sul.

A soma das condições favoráveis ao desenvolvimento da "região" Centro-Sul permitiu o surgimento de um centro do sistema capitalista nacional. A “região” Centro-Sul, beneficiando-se da regulamentação da relação capital-trabalho e do excedente de mão de obra gerado pelas migrações de trabalhadores nordestinos, assumiu a dianteira do sistema capitalista brasileiro, passando a concentrar e a centralizar capital. Esse processo de expansão capitalista fez com que as economias regionais começassem a ser destruídas, criando de fato um sistema capitalista em escala nacional.

Segundo Francisco de Oliveira, a disparidade existente entre a "região” Centro-Sul e o Nordeste brasileiro era visível, com total predo- 
mínio da primeira. As empresas nordestinas não conseguiam competir em preço nem em qualidade com as empresas localizadas na "região" Centro-Sul. Enfim, o processo de nacionalização do capital teria se realizado integrando as diversas regiões à lógica de reprodução do capital e teria utilizado as desigualdades geradas pelo processo de evolução capitalista para permitir a sua própria reprodução (OLIVEIRA, 1977, p. 37).

Para Oliveira, processo de nacionalização do capital referido acima teve forte presença do Estado e o "populismo" foi a forma política que o executou. Através deste processo de nacionalização, verificou-se a formação de uma burguesia industrial e a consequente redefinição das relações entre a burguesia industrial e a oligarquia do café. A partir de então, o Brasil se firma como um país capitalista que tem sua acumulação sustentada pela atividade industrial.

Podemos dizer que a grande diferença entre o que foi proposto por Celso Furtado e a crítica produzida por Francisco de Oliveira está no fato de que, enquanto Furtado tinha pretensões de intensificar o processo de acumulação capitalista no Nordeste, acreditando que assim seria possível desenvolver aquela região, Francisco de Oliveira afirmava que o atraso da região Nordeste fazia parte do processo pelo qual se expandia a atividade capitalista em todo o Brasil. Para Oliveira, a coexistência de regiões aparentemente opostas eram ferramenta para a própria expansão capitalista em escala nacional.

\section{Considerações finais}

Como foi observado acima, a interlocução crítica produzida por Francisco de Oliveira em relação a obra de Celso Furtado inseriu novos elementos teóricos que contribuíram para a interpretação do de- 
senvolvimento capitalista brasileiro. Em meio a um debate teórico intenso iniciado no final da década de 1960, Oliveira passou a discordar das teorias ortodoxas ao mesmo tempo em que começava a se despregar das análises cepalinas predominantes entre os teóricos que se opunham à teoria clássica.

Francisco de Oliveira não negava as contribuições da CEPAL e principalmente de Celso Furtado para o entendimento da realidade latino-americana, porém, demonstrava as lacunas existentes em sua interpretação. Seu objetivo maior era inserir novos elementos que pudessem complementar a interpretação de origem cepalina furtadiana no que se referia ao entendimento do processo de desenvolvimento capitalista brasileiro. Oliveira abordou esse tema de modo complexo cujo resultado foi realmente significativo, seja em termos da compreensão do processo de acumulação capitalista no Brasil, seja em termos de abertura de linhas teóricas de investigação.

Oliveira demonstrou que o processo de desenvolvimento capitalista brasileiro possuía algumas “especificidades” e que essas não poderiam deixar de ser consideradas. Discordava do "espontaneísmo" existente nas formulações furtadianas, como se o processo de industrialização tivesse ocorrido de maneira ocasional, sem a participação ativa do Estado. Oliveira evidenciou que o Estado sempre esteve presente desde o início no processo de expansão capitalista brasileiro, intervindo e planejando ao mesmo tempo em que regulamentava as relações entre capital e trabalho.

Francisco de Oliveira, utilizando-se da teoria marxista, voltou-se à análise das relações internas de produção, concluindo que a industrialização não foi permitida por fatores externos, como sustentada por Furtado, mas principalmente pelas condições internas. Dentre esses fatores, podemos citar o baixo custo da remuneração da força de tra- 
balho permitido através da estrutura agrária brasileira e do excedente de mão de obra gerado pelas migrações de retirantes nordestinos.

Essas inter-relações existentes entre as regiões "modernas" e "arcaicas” dentro do próprio espaço nacional, ao invés de serem antagônicas ao desenvolvimento capitalista nacional, como apresentado por Celso Furtado, eram a base para a expansão do sistema, que utilizava a desigualdade para se reproduzir. Tratava-se de uma coexistência entre setores aparentemente contraditórios, mas que serviam como ferramenta para a sua reprodução.

Francisco de Oliveira concluiu que o modo como o sistema capitalista brasileiro evoluía, alimentando-se da desigualdade, gerava uma intensa concentração de capital em poder de uma minoria burguesa. Porém, ao contrário do que Furtado afirmava, essa concentração não colocava em risco o processo de acumulação de capital, uma vez que era a própria desigualdade que alimentava todo o processo de reprodução ampliada do capital no brasileiro naquele período.

No que se refere à discussão com relação ao Nordeste brasileiro, podemos dizer que a interpretação que Francisco de Oliveira desenvolveu, dialogando com as teses furtadianas, contribuiu intensamente para a construção da " 'economia política' do planejamento regional para o Nordeste do Brasil” (OLIVEIRA, 1983) como o próprio autor ambicionava. Sua produção é um divisor de águas na literatura regional brasileira e embora não desconheça as contribuições da SUDENE para o desenvolvimento nordestino, Oliveira fez uma crítica contundente às suas formulações. $\mathrm{O}$ seu grande mérito foi inserir em sua análise os fatores sociais, políticos e históricos que fizeram parte do nosso processo de evolução econômica e social. Dessa forma, contribuiu para a interpretação da realidade regional brasileira e ampliou a discussão incialmente apresentada por Celso Furtado. 
As contribuições de Francisco de Oliveira, navegando nas águas da teoria da dependência e utilizando-se das formulações e categorias marxistas, produziu uma análise não-cepalina, forjando uma interpretação ampliada da realidade brasileira e se constituindo num interlocutor à altura das teses furtadianas.

A interlocução crítica produzida por Francisco de Oliveira à obra cepalina-furtadiana não deixou de considerar a importância que Celso Furtado exerceu e ainda exerce, sobre a produção teórica nacional. Podemos dizer que, embora a análise de Oliveira e a teoria furtadiana estejam em campos teóricos distintos, ambas confluem quanto ao objetivo de romper com as desigualdades existentes em nossa sociedade. No caso furtadiano, acreditava-se que uma política de planejamento, coordenada pelo Estado com objetivo de expandir a própria economia capitalista seria capaz de reduzir as mazelas geradas pelo capital, isto é, o pensamento furtadiano tem vocação para a ação e defende um capitalismo autônomo e reformado na periferia. Para Francisco de Oliveira, o capitalismo é, desde logo, um sistema injusto e desigual, sendo que as desigualdades não são contraditórias para sua própria forma de expansão.

Foi utilizando a crítica como sua maior ferramenta, que Francisco de Oliveira se transformou em um dos maiores interlocutores da obra de Celso Furtado. Citando sua própria análise a respeito da obra de Celso Furtado, Francisco de Oliveira considera que:

Elas talvez pareçam mais críticas do que deveriam ser. A obra de Furtado é, ela mesma, uma recusa ao ‘jeitinho' brasileiro; a crítica de sua obra também deve recusar essa 'ação entre amigos' em que se desenvolve boa parte da produção intelectual nacional. De mais a mais, não se conhece nenhum outro autor contemporâneo cuja influência no Brasil tenha alcançado os níveis que a obra de Furtado alcançou. (OLIVEIRA, 2003b). 
Podemos perceber também que Francisco de Oliveira considera que a obra furtadiana sempre foi digna de um debate, uma vez que considerava as especificidades do desenvolvimento capitalista nos países periféricos e recusou-se a interpretações convencionais defendidas historicamente pelo pensamento dominante.

Francisco de Oliveira sempre nutriu grande admiração por Celso Furtado, chegando a afirmar que ele era "um republicano exemplar" na medida em que sempre foi um cidadão íntegro, que dedicou grande parte de sua vida na busca de propostas factíveis para o Brasil.

Na verdade, Celso Furtado foi um grande intelectual brasileiro que influenciou várias gerações de cientistas sociais que surgiriam posteriormente, uma vez que sua obra foi, e ainda continua sendo, leitura obrigatória nos cursos de qualquer ciência social brasileira. Francisco de Oliveira o considera o “demiurgo do Brasil”, pela sua teorização e importante descrição da história econômica brasileira (OLIVEIRA, 2003b, p. 18).

Recuperar o pensamento de Celso Furtado, que sempre foi produzido para a ação, não é uma tarefa simples. Faze-lo passar pela prova da História, isto é, transformá-lo em agenda da política e de novo em ação é ainda mais difícil. Nos termos de Gramsci, a obra de Furtado tornou-se uma ideologia, vale dizer, uma forma de pensar o mundo latino-americano e informar a ação reformadora. Poucas produções teóricas podem se gabar dessa façanha. Marx já dizia que a teoria tem uma força transformadora insuspeitada quando é tomada pelos homens como arma na luta de classes. (OLIVEIRA, 2006, p. 2).

Oliveira dizia também que Furtado tinha grandes méritos por se propor a entender a realidade econômica nacional desvinculando-se das mesmices econômicas. Segundo ele, Celso Furtado foi contemporâneo de seu tempo, interpretando e teorizando no próprio momento em que os fatos ocorriam. Oliveira sempre sustentou que a obra de 
Celso Furtado tinha como objetivo a ação transformadora de tal forma que sua compreensão é tarefa necessária para a transformação social brasileira. Oliveira via na obra de Furtado o ponto de partida teórico capaz de elucidar as questões centrais do processo de desenvolvimento capitalista nacional, porém continuava defendendo a necessidade de executarmos um esforço teórico capaz de construir uma interpretação atual que fosse capaz de apresentar alternativas para a superação do atual cenário global.

Essa obra deve ser obrigatoriamente ponto de partida, não de chegada. Isto é, um enorme esforço teórico deve interrogar sobre as novas condições das nações em um capitalismo globalizado — ou mundializado, como prefere Chesnais - , bem como sobre os novos sujeitos da História e sobre as formações políticas (OLIVEIRA, 2006, p. 3).

Portanto, podemos dizer que a obra de Celso Furtado é ainda um terreno fértil e necessário para a compreensão e formulação de políticas que se proponham a transformar a sociedade brasileira, assim como, um debate crítico exercido com o devido rigor teórico, tal como realizado por Francisco de Oliveira, indica a maneira com o exercício intelectual contribui para a compreensão de nossa sociedade. Tratase de importantes pensadores brasileiros, nordestinos, que dedicaram todo seu trabalho no sentido de elaborar uma compreensão analítica com o intuito de transformar a realidade nacional. O exemplo deve ser seguido, principalmente em um cenário global onde o conservadorismo avança juntamente com a negação da ciência e do pensamento crítico, Franciscos e Furtados são a cada dia mais necessários. A república que ambos lutaram para construir agradece. 


\section{Referências}

BAVA, Silvio Caccia. Francisco de Oliveira, um militante. In: RIZEK, Cibele Saliba; ROMÃO, Wagner de Melo (Org.). Francisco de Oliveira: a tarefa da crítica. Belo Horizonte: Editora UFMG, 2006.

BELLO, Carlos Alberto. A economia política de Francisco de Oliveira e as expansões e crises econômicas brasileiras. In: RIZEK, Cibele Saliba; ROMÃO, Wagner de Melo (Org.). Francisco de Oliveira: a tarefa da crítica. Belo Horizonte: Editora UFMG, 2006.

BIELSCHOWSKY, Ricardo. Pensamento econômico brasileiro. O ciclo ideológico do desenvolvimentismo. Rio de Janeiro: IPEA/INPES, 1988.

. Ricardo (Org.). Cinquenta anos de pensamento na CEPAL. Rio de Janeiro: Record, 2000.

CARDOSO, Fernando Henrique; FALETTO, Enzo. Dependência e desenvolvimento na América Latina: ensaio de interpretação sociológica. 7. ed. Rio de Janeiro: Zahar, 1970.

FURTADO, Celso. A operação Nordeste. Rio de Janeiro: ISEB, 1959.

. Desenvolvimento e subdesenvolvimento. Rio de Janeiro: Fundo de Cultura, 1961.

Formação econômica do Brasil. 11. ed. São Paulo: Cia. Editora Nacional, 1972.

. Uma política de desenvolvimento econômico para o Nordeste. Revista econômica do Nordeste, 2. ed. v. 10, 1979.

. Subdesenvolvimento e estagnação na América Latina. 3. ed. Rio de Janeiro: Civilização Brasileira, 1968.

GUIMARÃES, Juarez. A Crítica à razão dualista e os impasses do republicanismo. In: RIZEK, Cibele Saliba; ROMÃO, Wagner de Melo (Org.). Francisco de Oliveira: a tarefa da crítica. Belo Horizonte: Editora UFMG, 2006.

Kuznets, Simon. Crecimiento econòmico y estructura económica. Barcelona: Gustavo Gili, 1970.

MAAR, Wolfgang Leo. A Teoria Crítica da Sociedade brasileira de Francisco de Oliveira. In: RIZEK, Cibele Saliba; ROMÃO, Wagner de Melo 
(Org.). Francisco de Oliveira: a tarefa da crítica. Belo Horizonte: Editora UFMG, 2006.

MANTEGA, Guido. A economia política Brasileira. 5. ed. Petrópolis: Vozes, 1990.

MANTEGA, Guido; REGO, José Márcio (Org.). Conversas com economistas brasileiros (II). São Paulo: Editora 34, 1999.

MALAN Pedro; PEREIRA, Jose E. de Carvalho. A Propósito de uma reinterpretação do desenvolvimento brasileiro desde os anos 30. Rio de Janeiro: IUPRJ, 1973.

OLIVEIRA, Francisco de. Elegia para uma re(li)gião: SUDENE, Nordeste, Planejamento e conflitos de classes. Rio de Janeiro: Paz e Terra, 1977.

. (Org.) Celso Furtado: economia. São Paulo: Ática, 1983.

1989.

A economia da dependência imperfeita. 4. ed. Rio de Janeiro: Graal,

. Crítica à razão dualista - O ornitorrinco. São Paulo: Boitempo, 2003a.

. A navegação venturosa, ensaios sobre Celso Furtado. São Paulo: Boitempo, 2003b.

. Para retomar a Construção Interrompida. In: Celso Furtado e o Século XXI. SABÓIA, João; CARVALHO, J. Cardim. Barueri, SP: Manole, 2006.

PAULANI, Leda. Arte de Francisco. In: RIZEK, Cibele Saliba; ROMÃO, Wagner de Melo (Org.). Francisco de Oliveira: a tarefa da crítica. Belo Horizonte: Editora UFMG, 2006.

PREBISCH, Raúl. O desenvolvimento econômico da América Latina e alguns de seus problemas principais. In: BIELSCHOWSKY, Ricardo (Org.). Cinquenta anos de pensamento na CEPAL. Rio de Janeiro: Record, 2000.

RIZEK, Cibele Saliba; ROMÃO, Wagner de Melo (Org.). Francisco de Oliveira: a tarefa da crítica. Belo Horizonte: Editora UFMG, 2006.

RODRIGUES, Octavio. Teoria do subdesenvolvimento da CEPAL. Rio de Janeiro: Forense Universitária, 1981.

SORJ, Bernardo. A construção intelectual do Brasil contemporâneo: da re- 
sistência à ditadura ao governo de FHC. Rio de Janeiro: Jorge Zahar Editor, 2001.

SCHWARZ, Roberto. Prefácio com perguntas. In: OLIVEIRA, Francisco. Crítica à razão dualista - O ornitorrinco. São Paulo: Boitempo, 2003.

TROTSKY, Leon. A história da revolução Russa. Vol. 1, Rio de Janeiro: Saga, 1967.

TAVARES, Ma. da Conceição; SERRA, José. Além da estagnação: uma discussão sobre o estilo de desenvolvimento recente do Brasil. In: BIELSCHOWSKY, Ricardo (Org.). Cinquenta anos de pensamento na CEPAL. Rio de Janeiro: Record, 2000. p. 589-608.

VIEIRA, Rosa Maria. Celso Furtado: reforma, política e ideologia (19501964). São Paulo: Educ, 2007. 


\section{Resumo:}

A interlocução crítica realizada pelo sociólogo Francisco de Oliveira à obra de Celso Furtado apresentou importantes contribuições para o entendimento da realidade brasileira e marcou o debate teórico nacional no período em que foi produzida. Este artigo tem como objetivo analisar os elementos centrais deste debate evidenciando as principais críticas apresentadas por Francisco de Oliveira ao pensamento furtadiano, principalmente quanto as relações de classe no âmbito interno, a importância que o Estado exerceu para permitir a acumulação capitalista brasileira e a funcionalidade que os setores "arcaicos” possuíram para a ampliação dos setores modernos. Com isso, verificaremos que essa interlocução teórica possui aspectos complementares e ratificam a necessidade da compreensão das obras desses importantes pensadores brasileiros que tanto contribuíram para o entendimento da realidade nacional.

Palavras-chave: Francisco de Oliveira; Celso Furtado; Economia Política; Economia Brasileira. 


\begin{abstract}
:
The critical analysis made by the sociologist Francisco de Oliveira about Celso Furtado's work presented important contributions to the understanding of the Brazilian reality and mark the national theoretical debate in the period in which it was produced. This article aims to analyze the central elements of this debate, confirming the main criticisms presented by Francisco de Oliveira to the Furtadian thought, especially regarding the class relations in the internal scope, the importance that the State exerted to allow the Brazilian capitalist accumulation and the functionality that the "archaic" sectors had for the expansion of modern sectors. With this, we will verify that this theoretical debate has complementary aspects and ratify the need for understanding the work of these important Brazilian thinkers who contributed so much to the understanding of the national reality.
\end{abstract}

Keywords: Francisco de Oliveira; Celso Furtado; Political Economy; Brazilian Economy.

Recebido para publicação em 29/07/2019. Aceito em 22/11/2019. 